\title{
Aspects of anthropotechnics reliability of materials and products for non-collapsible and collapsible systems in high-rise construction
}

\author{
Ruben Kazaryan ${ }^{1, *}$ \\ ${ }^{1}$ Moscow State University of Civil Engineering, 129337, 26, Yaroslavskoe shosse, Moscow, Russia
}

\begin{abstract}
In engineering systems, which are used in construction industry and its production (buildings, constructions, roads), two fundamentally different ways of mechanical joint are used: non-collapsible and collapsible. Some architects relate non-collapsible objects to monolithic and consider their recycling as a difficult and expensive process. Compression joints on self-locking fittings can be considered as non-collapsible as well. A compression connection cannot be disassembled without destroying. Collapsible joint differs from non-collapsible by the following features: 1 . You can disassemble it to original components according to a prior technology, identify and change defective elements or add some other components. 2. It requires periodic inspection and maintenance because of climatic conditions (temperature changes, pressure changes, wind loads, etc.), and the specificity of operation of this joint leads to a decrease in its mechanical properties. 3. It is forbidden to make them monolithic, so collapsible joints are mounted in an accessible way. Collapsible finishing system is a new fundamental direction of building reconstruction in the TTS system "man-technology- environment" in high-rise construction objects.
\end{abstract}

\section{Introduction}

There are two kinds of components: the reinforcing (which provides the necessary mechanical properties of the composite) and the binder component (or solution) (which provides collaboration of reinforcing components). The ratio of the properties of the reinforcing components and the binder, as well as bonds between them, determines the mechanical properties of the composite. Composite demonstrates the properties of both mixed elements. In composites, the increasing of static strength leads to the increasing of its viscosity properties [1]. Two states are distinguished in the creation and fabrication of the composites: 1. Statics as a set of values of the parameters of the composite. Composite statics is captured by instrumental and technical or model and analytical diagnostics, which registers the degree of balance of composite parameter values. 2. Dynamics as a sequence of static states of a composite. Composite dynamics is captured by statistical or computer monitoring, which suggests the identification of a further evolution (which may not occur). The effect,

\footnotetext{
Corresponding author: r.kazarian@ mail.ru
} 
which is achieved by components when they are combining into a composite, is the most important thing.

\section{Materials and methods}

Modern collapsible systems for finishing buildings and constructions used both for interior planning and protection of outer enclosing surfaces and structures from harmful environmental influences. Using of these collapsible systems of finishing allows effectively solving problems of operation of a building or a structure, its durability and indoor ecology [2].

Collapsible systems of finishing provide the implementation of one of the new modern varieties of building reconstruction - Retrieval. The study of regularities, properties, and terminology of retrieval is just the beginning, and as often happens, practice is ahead of researches. Every sector of construction business uses the most appropriate name for their own collapsible system of finishing: facade systems, translucent finishing systems, planar glazing, glass facades, wall cladding system, ventilated facades, wet facades, hinged facades, etc [3]. All listed names represent special cases of implementation of hinged retrieval systems of finishing - composite structures made of different materials, depending on many factors. It can provide the outer insulation of enclosing structures to improve the microclimate of the interior [4].

Hinged ventilated facade (HVF) consists of cladding and construction which is fixed to the wall with a little air gap between the protective-decorative coating and the wall. When designing structures of HVF, special attention is paid to the possibility of free aircirculation in the air gap of the facade structure. For tall buildings, it is necessary to calculate the air circulation in the air gap, so an unobstructed and efficient airflow over the entire surface of the wall could be provided [5]. Due to the differential pressure, this gap works as a "chimney"

- it creates an upflow, which carries excess heat, atmospheric and internal moisture away. Ventilated air gap reduces heat loss.

\section{Results}

The structural systems, which are protected with HVF, function almost perfectly: there is no direct effect of atmospheric factors; materials are not affected with biological destruction. The wall of the building remains dry and warm: HVF protects it from temperature fluctuations. In summer, HVF works like sun-shielding screen reflecting an essential part of the heat flux incident on it.

To product the HVF, it is necessary to use auxiliary elements from hardly combustible or incombustible materials and widgets that prevent the spread of fire. As an example, it can be sealing tapes between the inner surface of the sun-shielding screen, decorative corners and inserts for closing the gaps between the panels; perforated steel structures for ventilation of the system from below and above [6].

Specially designed structures and special mounting scheme allow absorbing thermal deformations arising at seasonal temperature differences, avoiding internal tensions in the materials of the sun-shielding screen and frame, which reduces the likelihood of cracks and destruction of HVF.

HVF advantages are:

wide range of modern facade decoration materials;

- $\quad$ high level of thermal and sound insulation;

- $\quad$ effective ventilation of atmospheric moisture formed due to diffusion and water vapor from the interior of the building; 
- $\quad$ wall protection and thermal insulation from atmospheric influences;

- compensation of thermal deformations;

- $\quad$ possibility of mounting and reconstruction facade works at any time of year;

- $\quad$ no special requirements to the surface of the bearing wall of the building;

- $\quad$ a long overhaul period (25-50 years, depending on the materials used);

- $\quad$ fixing the insulation on the external surface of the building wall with the help of dowels or special profiles;

- mobility of joints to compensate the dynamic loads (wind, temperature changes, etc.);

- possibility of compensation of unevenness of the bearing wall of the building;

- $\quad$ simplicity and fast installation speed of all HVF components.

The Russian market presents a large number of different systems of domestic and foreign manufacturers for hinged ventilated facades.

Domestic: «Alkon Treyd» (U-kon), «Diat», «Kaptekhnostroy» and «Mosmek», factory

«Metallokonstruktsiya» (KTTs), «Tekhnokom», «Arkada» etc.; Austrian: Slavonia (Spidi), Eurofox (represented in Russia by «Dyuvils» and «Mirazh»); German: BWM, WAGNER- SISTEM (represented by «Tekhnokom»); Dutch: Hunter Duglas.

Each of these HVF systems has a number of design features that ensure its optimality in solving specific problems (for example, leveling the unevenness of the bearing wall of the building, ensuring reliable mounting of heat-insulating slabs, ensuring the possibility of fastening small-sized cladding without a significant rise of the cost of the frame, etc.) [7, 8].

\section{Discussion}

The appearance of facades in Russia is accompanied by a number of problems, which are not known to foreign manufacturers of these systems (significant unevenness of the walls, very significant differences in winter and summer temperatures, etc.) They force builders to adapt any foreign HVF system to Russian conditions. A number of specific features of such adaptation will be considered below.

Reliable attachment of HVF to the bearing wall of the building is ensured by brackets, which made of different metals (aluminum, galvanized or stainless steel) and attached to the wall of the building with special anchoring elements (dowels, screws, anchors, etc.). The parameters (diameter and depth of the walling of these fasteners) are selected depending on the "pulling" load and the material of the wall which has the mounted bracket. The brackets must withstand static and dynamic loads; provide the ability to mount timber framing on uneven walls. Therefore, the most important characteristics of the bracket are the bearing capacity and the possibility of changing its length. To fix the unevenness of the wall, it is necessary to: 1 . Have a large number of bracket sizes; 2 . Use brackets with wide variation limits. Both options allow you to move from the wall for a distance of $0.5 \mathrm{~m}$. The brackets with the possibility of a significant change in their length have three standard sizes; the length of each of these brackets is infinitely adjustable within $13 \mathrm{~cm}$, which allows you to move from the wall at any distance within the above limits [9]. At the design stage of new construction, the calculation of the number of brackets of a certain size is carried out on the assumption that the walls will be even. During construction and installation work, it is often found out that the imported elements of certain sizes cannot provide the necessary evenness of the walls and it is necessary to order other sizes, which also leads to a general rise in the cost of HVF and the processes of its installation. This problem does not occur when using variable length brackets. When analyzing the structural features of the brackets, a problem occurs of possible formation of "cold bridges". There are two ways to solve this problem: 1. Reduction of the contact area of the metal with the wall; 2. Application of different insulating gaskets (foreign companies use 
different plastics, Russian companies often use an effective heat-insulator "paronite") [10]. Both ways have advantages and disadvantages. With reduction of the contact area, the thermal conductivity is lower, but at the same time, it reduces the load-carrying capacity of the brackets to the wall. With increasing contact area, the problem of forming "cold bridges" becomes more serious. The timber framing consists of anti-corrosion profiles (aluminum, stainless or galvanized steel, master alloys or antiseptic impregnated wood). Different profiles are used for different facades. Three types of profile timber framing are used: horizontal, vertical, and combined. The worst dimensional construction is horizontal because of the profile works on bending and torsion. In the structure of vertical guide, profiles perceive the load on compression and tension (which is more favorable); in addition, this structure does not interfere with the main vertical airflow. The best is the combined construction in which horizontal guides are fastened to the wall, and to them vertical guides, which respond to the load from the cladding slabs. This structure redistributes the load and does not create obstacles to vertical airflow. At the same time, the combined design is quite metal consuming and is represented on the Russian market only by foreign manufacturers. There is a combined construction of a different type (which is hidden at external inspection of fasteners). Vertical guides are fastened to the bearing wall of the building, and to them - horizontal. This structure inherits all the disadvantages of a horizontal structure, so it is used for thick-walled cladding of slabs made of natural stone, which are attached to the horizontal longitudinal guide cuts in the slab. In this case, the horizontal guides experience loads on vertical lateral compression, which allows the timber framing to function qualitatively. This structure has a lot of advantages:1. Each fixing plate is fastened to two separate horizontal guides, which reduces the load on each of the guides;

2. Increased distance of the cladding tiles from the insulation, which contributes to the effectiveness of the air gap [11]. Cladding panels are conventionally divided into three groups: 1. Heavy (natural stones); 2. Light (granite, cement-fiber slabs, etc.); 3. Selfsupporting products made of different materials (metal, glass, plastic, etc.).

For each group, a special kind of sub-structure is used. Heavy cladding tiles require a more powerful, material-intensive and more expensive sub-structure. Plates of heatinsulating material are installed between the supporting profiles and fastened directly to the wall of the building. With insufficiently strong fastening, there is a danger of the sliding of tiles and formation of gaps between them - "cold bridges", therefore, additional fastening of tiles of a heat-insulating material is provided [12]. Fasteners carry out mechanical fastening of cladding materials to the bearing profiles of the sub-structure. There are visible and hidden fasteners. Visible fasteners are simpler; they are carried out with clamps, self-tapping screws or rivets. To give the whole structure a single color, the leading manufacturers of fasteners paint its visible parts with powder paint in the color of the cladding material. Fastening elements often painted and supplied by the manufacturers of cladding tiles. The clamps allow easy installation of the cladding tiles, don't let the tile to vibrate during wind gusts, and ensure reliable fastening. Both types of fastening (hidden and visible) provide a fairly easy and quick fastening of the cladding tiles to the supporting structure. Hidden fastening requires additional processing of cladding tiles to strengthen them (first of all, this applies to porcelain stoneware, minerit, etc.), which leads to an increase in the cost of HVF. To exclude the possibility of cracks and destruction of the cladding tiles, it is necessary to ensure the required mobility of the joints of these tiles with the sub-structure, which cannot be the same for all types of buildings. In order to select and calculate the required range of fasteners and substructure, leading firms require the customer to provide some information (climatic region; location; height and configuration of the building; the type of the bearing wall; thickness and type of insulation; type of cladding). Only by performing an analysis of all these data and making the appropriate calculation, you can select the product range that corresponds to the particular facade of the building and calculate the cost of the sub-structure. The calculation 
of HVF structure can only be made by professional. It is necessary to be responsible for choosing the cladding material of bearing walls, especially wall-filling in monolithic house construction. In buildings with a height of more than $40 \mathrm{~m}$, wind loads are close to the weight of the ventilated facade and even exceed it at critical points. With insufficient bearing capacity of the building wall, the brackets have to be installed much more often and it is necessary to use more expensive anchoring elements, which leads to a rise in the cost of the sub-structure. It could be determined by calculation that it is more advantageous to use cheap wall material and get a rise in the price of the sub-structure of the ventilated facade. Or you can use a better (in terms of bearing capacity), albeit a more expensive material for the walls. Thermal insulation material of HVF has to: 1 . Be resistant to wind flow, non-corrosive to metal, durable, non-flammable, and resistant to aging material; 2. Have a stable shape, ensure its installation, excluding the emergence of "cold bridges"; 3. Have high thermal insulation characteristics; 4 . To allow water vapor and moisture to enter the air layer, preventing the formation and accumulation of the condensate on the structures. In ventilated facades, mineral wool is often used as a heater, sometimes glass wool. These materials have high heatabsorbing and noise-absorbing properties, and also represent an unfavorable environment for the formation of mold. Particular attention in choosing a thermal insulation material is drawn to the possibility of the occurrence of powerful air currents in the ventilation gap of the structure, which can lead to the destruction of the upper layers of the soft thermal insulation material. The heater is protected from the effects of air currents using a windproof vaporpermeable film (for example, Tyvek), laminated heat insulation slabs, rigid heat-insulating slabs, or double-layer mineral wool slabs. When using two-layer mineral wool slabs, they are installed more densely, outside the facade structures, and less densely - directly on the bearing wall (for better fitting of the insulation to the unevenness of the insulated structure).

Not all specialists in the construction industry understand the need for a windproof film. There is an opinion that even the use of rigid heat-insulating slabs does not make the wind protection superfluous (if you take into account that the cost of it is negligible, compared with the overall cost of HVF structure). The slabs of the heater are tightly fitted to each other and pressed against the supporting wall by the plastic dowels. The dowel parameters (type and size) are determined by calculation and are refined after carrying out (if necessary) some tests for equalization and shearing forces, heat resistance and frost resistance. The following types of cladding products are fabricated: large and small panels, siding (long narrow panels), and profiled (fibrous) sheets. Consider the most common cladding materials. Vinyl siding formatted from polyvinyl chloride (PVC) panels, with a thickness of about one millimeter, a length of 3-4 m, and its maximum width of $20-25 \mathrm{~cm}$, imitating board lining. The shape of the panels is different for different manufacturers and in different series from one manufacturer. On one side, along the length of the panel, vinyl siding has holes for piercing with nails, and on the other, there are projections for attaching the panels to each other. The panels are lapped, the lock of the upper panel engages with the projection on the bottom. The panel is fixed to the base with nails or self-tapping screws. Wet facade is formed with the thin-layer plaster in the process of repair and finishing works mainly on historic sites where it is important to keep the architectural appearance of the building or structure unchanged. Installation and finishing of this facade is carried out in a warm, dry season.

\section{Conclusions}

In European countries, "wet" facades are erected by attaching thermal insulation material to the wall surface with glue and mechanical joints, and then applying plaster, fiberglass, and synthetic materials to it. This technology provides a special color and texture solution of facades, warming slopes, less labor-intensive work, and the possibility of further renovation of the facade in the process of reorganization. The best modern thermal insulation materials 
(foam plastics and mineral wool products) have a density that is 5-15 times lower than wood; so their thermal conductivity is many times lower than wood's. These materials create the necessary heat-insulating effect with a small thickness of the material layer. For example, a brick wall of 2.5 bricks (which is $64 \mathrm{~cm}$ ) corresponds to a layer of foam plastic $3 \mathrm{~cm}$ thick by thermal conductivity. Reinforced layer of the adhesive solution with a glass net is formed on insulator, and then a decorative plaster layer is applied [13].

The main advantage of domestic heat-insulating and waterproofing materials is a low price, but their quality isn't great. In recent years, trends in the development of domestic production have marked a gradual increase in quality control and, as a result, the quality has improved [14-17].

For now, imported components are dominating in the systems of "wet" facades, and it is difficult to distinguish an undoubted leader in the production of high-quality domestic materials and components for the technology of a "wet" facade. So, construction firms which provide a guarantee for their work prefer the systems of «ATLAS», Tex-Color, and Serporok. Collapsible finishing system is a new fundamental direction of building reconstruction.

In the context of the reorganization of public administration and the public formation, changes in the methods and means of engineering diagnostics and monitoring, the scope of application of such an important criterion as organizational and technological reliability (OTR) has significantly expanded. New directions for the development of OTR appeared:

- organizational and economic reliability (OER);

- organizational and legal reliability (OLR), which guarantees the inclusion of innovations in the information technologies of building rule-making and law-making;

- organizational and technological flexibility and reliability (OTFR), which guarantees the fastest possible response to changes in the state of construction production;

- organizational and anthropotechnical reliability (OAR), which guarantees the diagnosis, monitoring and ensuring the safety of human production and vital functions in construction.

These new organizational forms of the development of OTR turned out to be much more complicated than purely technical systems, since they contain human interaction with the external environment. This interaction is probabilistic, specific for each individual person, has an individual character. In this regard, for each person there is his personal norm of interaction with the external environment and adaptation to it (adaptive norm of a specific person). The study of the specifics of the formation of an adaptive human norm, its manifestation and compensation of the pathologies that arise in order to ensure the safety of human life and productive activity is one of the most important tasks of science in a democratic society.

A systematic approach to studying the laws, properties and terminology of this area will provide an understanding of the integrated assessment of the practical understanding of the business processes of building reconstruction in the TTS system "man-technologyenvironment" in high-rise construction objects.

\section{References}

1. V.O. Chulkov, O.N. Kuzina Orgaizational-technological criteria of arrangement of construction renovation varieties, 410-426 (2010)

2. V.O. Chulkov, O.N.Kuzina Retrieving - innovative direction in a functional system of construction renovation, 439-443 (2010)

3. A.A. Volkov, V.O. Chulkov, G.O. Chulkov, R.R. Kazaryan, O.N. Kyzina Qualities of documentation management chain 2, 1065-1069, 2401-2404 (2015)

4. A.A. Volkov, V.O. Chulkov, G.O. Chulkov, R.R. Kazaryan, O.N. Kyzina Qualities of documentation management chain 2, 1065-1069, 2405-2408 (2015) 
5. A.A. Volkov, V.O. Chulkov, G.O. Chulkov, R.R. Kazaryan, O.N. Kyzina Qualities of documentation management chain 3, 1065-1069, 2405-2408 (2015);

6. A.G. Tamrazjan, N.V. Fedorova Reliability assessment of reinforced concrete structures reinforced with coal-technology textile industry 6, 226-231 (2016)

7. A.G. Tamrazjan., A.L. Zholobov, N.A. Ivannikova Technologies for inspection of plastered surfaces of complex architectural forms of building structures by geometric modeling methods 11, 125-130 (2012)

8. B. Zhadanovsky, S. Sinenko E3S Web of Conferences Series "High-Rise Construction 2017, (2018)

9. S. Novikov, B. Zhadanovsky, S. Sinenko 22nd International Conference on Innovative Manufacturing Engineering and Energy, IManE and E 2018, 6011 (2018)

10. S. Novikov, B. Zhadanovsky, S. Sinenko 22nd International Conference on Innovative Manufacturing Engineering and Energy, IManE and E 2018, 9007 (2018)

11. S Sinenko, B Zhadanovskiy, L. Pakhomova Materials Science and Engineering 463 (2018), 032032 IOP Publishing doi:10.1088/1757-899X/463/3/032032.

12. S.A. Sinenko, A.O. Feldman Materials Science and Engineering 463 (2018), 042010. IOP Publishing doi:10.1088/1757-899X/463/4/042010.

13. S.A. Sinenko, B.V. Zhadanovskiy, S.A. Moiseeva Materials Science and Engineering 463 (2018), 042039 IOP Publishing doi:10.1088/1757-899X/463/4/042039 doi:10.1088/1757-899X/463/4/042039.

14. S.X. Zeng, V.W.Y. Tam, S.M. Tam Safety science 8,1155-1168 (2008) http://www.sciencedirect.com

15. K. Dana, D. Smith, Alan Edgar. BIM. Whole building design guide of National Institute of Building Sciences. URL: http://www.wbdg.org/bim/bim.php.

16. E. Avdeeva, T. Davydova, N. Skripnikova, L. Kochetova, E3S Web of Conferences, 110, 02139 (2019) https://doi.org/10.1051/e3sconf/201911002139.

17. R.R. Kazaryan, V.O. Chulkov V.O. Sci Rev Regarding some aspects of improvement of construction products quality 24 (2015) 